\title{
(Re)conociendo Mondoñedo. El pasado se proyecta como futuro
}

\section{(Re)cognizing Mondoñedo: The Past Projects Itself as Future}

\author{
Elena Freire Paz \\ Departamento de Filosofía y Antropología Social \\ Universidade de Santiago de Compostela
}

\section{RESUMEN}

La autora se acerca a la realidad socio-cultural actual creada en Mondoñedo, ciudad del interior de la provincia de Lugo (Galicia, España), teniendo en cuenta las bruscas transformaciones económicas, sociales y culturales acontecidas en las últimas décadas. $\mathrm{Si}$, desde una perspectiva externa, el movimiento económico global ha motivado la transformación de determinadas pautas culturales en todo el mundo, los cambios propiciados desde el interior de cualquier sistema cultural han repercutido en la génesis de una interesante planificación de marcado carácter cultural. El desarrollo local de la zona gira en torno al aprovechamiento de determinados recursos culturales como impulsores y dinamizadores de un territorio estrangulado por un fuerte descenso poblacional, la pérdida de consideración hegemónica de la villa frente a la capitalidad de la provincia, el abandono del sector primario y la escasez de actividades del sector secundario.

Palabras clave: Globalización, Galicia, Patrimonio cultural, Desarrollo local, Turismo.

\section{SUMMARY}

The author approaches the current socio-cultural reality in the town of Mondonedo (province of Lugo, Galicia, Spain) by considering the rapid economic, social and cultural changes that have taken place there over the past few decades. Whereas from an outside perspective the global economic process has resulted in the transformation of certain cultural patterns everywhere, the changes occurred inside any cultural system have brought about the inception of an interesting strategy of a clearly cultural character. Local development in Mondoñedo nowadays rests on making the most of specific cultural resources so as to prompt and energize an area affected by a sharp population decline. The current context also includes the loss of the town's provincial hegemony to Lugo, the capital, the demise of primary activities and the meagre implementation of secondary activities.

Key words: Globalization, Galicia, Cultural Heritage, Local Development, Tourism. 


\section{MARCO GENERAL}

Pensar el mundo actual al margen de la globalización ya no es posible y, de hecho, este fenómeno "constituye hoy uno de los nuevos referentes conceptuales para explicar los procesos sociales" (Aguilar 2003) que conforman el campo de estudio de la disciplina antropológica desde la que enfocamos este análisis. Así pues, todas las realidades sociales están hoy condicionadas por un fenómeno de naturaleza transversal que tuvo un origen económico, pero que ya ha traspasado las diversas fronteras que durante años habían separado e identificado el ser de los pueblos, las comunidades y las naciones. La globalización supone la homogeneización, la presencia, más o menos impositiva o invasiva, de unos mismos patrones de conducta consumista que terminan por igualar la oferta y la demanda en cualquier parte del mundo. Escapar a este sistema, que funciona como el operador más eficaz del capitalismo económico, es prácticamente imposible.

En este contexto mundial se enraízan las coordenadas en las que se inscriben los profundos cambios que se han producido de manera muy rápida, casi brusca, en sociedades tradicionales, como la gallega, cuyo estudio centra nuestro interés. Tal situación afecta a una organización social que ha pasado de poseer una amplia base integrada en el sector primario a tener que plantearse el futuro en función de las opciones turísticas que puede ofertar, es decir, orientada hacia el sector terciario. Esta reorientación en cuanto a los sectores productivos no se debe, sin embargo, a una evolución interna del propio sistema; por el contrario las leyes del mercado mundial actual no permiten compatibilizar la pertenencia a un sistema capitalista con la pervivencia de economías agrarias dedicadas en su mayor parte al autoconsumo y a la subsistencia mediante una agricultura de policultivo que garantizaba la consecución directa de los productos necesarios para la dieta, tanto humana como de los animales domésticos, imprescindibles, a su vez, para llevar a cabo los trabajos agrícolas. Nos encontramos, por lo tanto, ante una transformación indirecta suscitada desde fuera $^{1}$ de las sociedades que la experimentan y que afecta a ese conjunto de manera integral, es decir, modificando no sólo los modelos productivos sino, también, el comportamiento social y a las producciones culturales que los acompañan.

\footnotetext{
${ }^{1}$ La existencia de cambios exógenos que afectan a las poblaciones locales no son per se algo novedoso, pero sí lo es la velocidad que caracteriza a los derivados de la globalización actual en la que la movilidad de personas e información es absoluta.
} 
Desde una perspectiva histórica y sociológica, parece obvio que el estado de cosas al que nos referimos se enmarca en un debate netamente contemporáneo, en tanto que no parece surgir, al menos en primera instancia o de manera directa, de las transformaciones operadas en las sociedades industriales con el paso desde el sistema socio-económico preindustrial a la modernidad. En efecto, el ámbito social, económico y cultural al que nos referimos - en este caso, el medio semi-urbano o semi-rural de Mondoñedo, pero, por extensión, todo el medio rural gallego - se ha mantenido históricamente en un contexto netamente preindustrial, sin sufrir transformaciones aparentes con los cambios asociados a las sociedades industriales modernas. Así, su sistema de subsistencia principal —el sector primario- se ha mantenido, de manera invariable, hasta la actualidad, en que viene a confluir con las necesidades postindustriales derivadas, justamente, de la necesidad de desarticular ese arcaico sistema económico para atraerlo al ámbito económico actual, no mediante la creación de una serie de condiciones industriales, sino, precisamente por la imposibilidad de esta opción, a través de un retorno a formas tradicionales de subsistencia que han sido dotadas de nuevos roles en lo económico, lo social y lo cultural. Hablaríamos, pues, de una especie de elisión o lapsus temporal, según el cual el mundo tradicional gallego sería introducido directamente en la contingencia económica que rige la postmodernidad o la globalización, sin haber pasado por el estado previo de la industrialización o de la "modernidad".

En este contexto de cambio, proponemos observar la descripción de los diferentes elementos que articulan el proceso de patrimonialización de la producción cultural tradicional en una comarca del interior de la provincia de Lugo con el fin de intentar acceder al mercado mundial a través de la incorporación de una oferta turística basada en productos artesanales. El estudio de este caso concreto es una aportación etnográfica desde Galicia de cómo "a pesar de que la cultura y el patrimonio cultural son cada vez más transterritoriales, estos son fijados, condensados y apropiados por grupos humanos concretos que tienden a territorializarlos" (Pereiro y Sierra 2005: 14).

Retomando nuestro discurso, la sociedad gallega tradicional, al igual que otras muchas, se caracterizaba por una forma de producción inserta en un modelo circular, en el que los sucesivos ciclos anuales marcaban no sólo el tiempo cronológico, sino también el social; esta situación era la que definía la mayor parte del territorio hasta hace poco más de treinta años. Fue entonces, aproximadamente en la década de los años setenta del siglo Xx, cuando comenzó un cambio que, a la postre, sería radical. En el ámbito rural gallego, la mano de obra había disminuido considerablemente como 
consecuencia de las sucesivas olas migratorias ${ }^{2}$ planteadas como la única alternativa para alcanzar una mínima prosperidad, y el abandono del campo se hizo cada vez más notorio. Al mismo tiempo, se exigió que las explotaciones agrícolas y ganaderas que mantenían su actividad mejorasen sus rendimientos, que entrasen en la "modernidad" y se adecuasen a los nuevos tiempos para hacerlas más rentables desde unos parámetros estrictamente productivos, buscando el mayor aumento posible desde un punto de vista cuantitativo. Esto supuso, entre otras cosas, la implantación de unos objetivos unilineales hacia el progreso buscando ser competitivos y, por tanto, una ruptura total con aquella producción en círculos sucesivos, sin principio ni fin, que enlazaba la rutina y la dureza de las labores cotidianas con la simbología de las ancestrales y míticas espirales de los petroglifos ${ }^{3}$. Este corte afectó no sólo a la forma de trabajar en el sector primario, sino también a las estructuras simbólicas de la cultura y a las construcciones sociales que se habían instaurado y acoplado a aquel modelo de producción. En este sentido, afirma García Canclini que "si toda producción cultural surge, como vimos, de las condiciones materiales de vida y está arraigada en ellas, aún más fácil es comprobarlo en las clases populares, donde las canciones, las creencias y las fiestas están estrecha y cotidianamente ligadas a los trabajos materiales en que entregan casi todo su tiempo" (García Canclini 1989: 61).

La introducción de maquinaria para facilitar el trabajo y como símbolo de modernidad, la utilización de semillas tratadas, junto a pesticidas y abonos químicos para aumentar la productividad de ciertos monocultivos que se priorizaron, la extensión de una cabaña bovina orientada a la producción láctea, la plantación masiva de determinadas especies forestales como el pino y el eucalipto, incluso el nuevo reparto de la tierra mediante la aplicación de concentraciones parcelarias que permitían la utilización de

${ }^{2}$ A este respecto se pueden consultar las numerosas obras de Xosé Manuel Nuñez Seixas o Pilar Cagiao Vila, en las que se analizan los diferentes movimientos de la emigración gallega que, si hasta bien entrado el siglo xx tuvo como destino preferente el otro lado del Atlántico, a partir de la segunda mitad de esa centuria se inclina hacia otros países europeos, siempre compartida con las ciudades españolas de mayor crecimiento que funcionaban también como polos de atracción de los emigrantes gallegos.

${ }^{3}$ Resulta interesante observar cómo la cotidianeidad de los trabajos agrícolas y su secuencialización se adecuan al trazado laberíntico de la simbología de origen celta poniendo en conexión una forma de vida y unos referentes míticos ancestrales. En esta vinculación entre lo que representa la "esencialidad" del ser gallego y un modo de producción se aprecia la idea de que "cualquier práctica es simultáneamente económica y simbólica, a la vez que actuamos a través de ella nos la representamos atribuyéndole un significado" (García Canclini 1989: 44). 
maquinaria agrícola de todo tipo supuso, al mismo tiempo que se avanzaba en una idea económica de progreso, el desmoronamiento de un sistema social surgido ad hoc para las condiciones propias de una sociedad anterior a la "modernidad" y, todo ello, sin que dejase de disminuir el sangrado poblacional del campo. Las reformas agrícolas tan proclamadas por los políticos del momento, que llevarían a una sociedad atrasada hacia el avance imparable de lo moderno, no llegaron a encajar totalmente, entre otras razones, por ejemplo, porque la producción nunca llegó a cumplir los mínimos de rentabilidad exigidos en cuanto a costes de producción y de competitividad a nivel internacional. Además, las políticas de subvención llevadas a cabo por los organismos responsables —véase la Unión Europea, en la que España entra en 1982- y que supusieron un refuerzo más en la ya mencionada inmersión en la modernidad a la que había que aspirar a toda costa, sólo llevaron a un problema de superproducción, con numerosos excedentes agrícolas que no tenían salida en el mercado mundial, aún cuando suponían el capítulo fundamental del presupuesto comunitario.

En el caso gallego, que aquí nos ocupa, todavía hoy la cuestión de la cuota láctea es un tema candente que afecta a una gran cantidad de pequeños productores a los que no se les permite que sus explotaciones y niveles productivos crezcan, obstruyéndoles así la única posibilidad de competir en un mercado regido por un abaratamiento constante del producto que sólo puede ser paliado, al menos en cierta medida, por un incremento continuado de la cantidad producida. Así, mientras el sector primario, ocupación básica de una gran cantidad de población hasta no hace mucho tiempo - en 1997, el 22,2\% frente al 5,0\% de Europa-, no parece factible como motor de desarrollo, y teniendo en cuenta que el sector secundario nunca ha jugado en la economía gallega el papel que tuvo en otras zonas del Estado, el sector terciario parece constituirse como la posibilidad de futuro más importante. Según el informe elaborado por el Instituto Galego de Estadística para el año 2006, "en Galicia o sector servizos é o que acada unha maior representación en termos de ocupación e así, neste sector empréganse case o $60 \%$ dos ocupados galegos" (IGE 2006: 10). Los datos de distribución laboral son los que figuran en la siguiente tabla: 


\begin{tabular}{cccc} 
Año & Agricultura y pesca & & Servicios \\
\cline { 1 - 1 } 1996 & 230,6 & 464,2 \\
1997 & 194,7 & 475,9 \\
1998 & 181,4 & 496,6 \\
1999 & 172,5 & 513,6 \\
2000 & 174,3 & 537,7 \\
2001 & 156,3 & 551,2 \\
2002 & 136,4 & 561,3 \\
2003 & 135,6 & 602,1 \\
2004 & 124,6 & 621,5 \\
2005 & 120,9 & 666,7 \\
2006 & 110,9 & 700,5 \\
2007 & 103,1 & 725,7 \\
2008 & 96,4 & 756,5 \\
\hline
\end{tabular}

FuENTE: Instituto Galego de Estadística. Población ocupada por sectores económicos (medias anuales). Datos en miles de personas.

Como ya hemos adelantado, el cambio de orientación del sector productivo primario hacia el terciario en zonas como Galicia no ha surgido por una evolución endógena del sistema productivo, sino que ha sido inducido desde el exterior mediante el refuerzo de la aplicación de las políticas a nivel mundial que plantean ese salto como el mejor modo de acomodación a los tiempos de la modernidad en los que viven sus actuales habitantes, tanto los reales, la población autóctona, como los potenciales, es decir, los turistas $^{4}$. El hecho de que el planteamiento de las posibilidades de desarrollo haya sido exógeno es fundamental para vincularlo con una actividad turística que encaja en la mentalidad urbana de quienes lo proponen, pero que

\footnotetext{
${ }^{4}$ Un rasgo propio de la sociedad contemporánea fue la conjugación de varios factores que potenciaron la eclosión del turismo como actividad lúdica para ocupar el tiempo de descanso. En un primer momento, durante el siglo XIX y parte del XX, el reposo estaba prácticamente restringido a las élites burguesas y asociado a los balnearios y tratamientos termales, muy relacionado con el bienestar y la relajación física. Desde los años 60 del pasado siglo, las mejoras laborales de las clases trabajadoras en cuanto a salarios y a períodos vacacionales, así como la evolución de las infraestructuras y de los medios de transporte, hicieron que una cantidad de población, cada vez mayor, de los países más prósperos adoptase como hábito de consumo los períodos vacacionales asociados a las prácticas turísticas. Se asoció el consumo del tiempo libre y la diversión con la movilidad espacial, con el conocimiento de otras realidades geográficas y, por extensión, culturales. Así las cosas, en el momento actual, cualquiera puede trasladarse a otro lugar durante unos días o incluso durante unas horas en las que pasa a formar parte, como turista, de la comunidad que visita. Según la Organización Mundial del Turismo, en el año 2006, 842 millones de personas practicaron turismo.
} 
necesita ser asimilado y adoptado por las comunidades que lo van a explotar como recurso y que, a priori, están más lejos de ese enfoque global, urbano y cosmopolita.

En realidad, en la noción misma de la artesanía, a la que nos referiremos a lo largo del artículo, van implícitos los ítems caracterizadores de las sociedades tradicionales: dependencia de un sistema productivo primario, agrícola y ganadero, y ausencia de alternativas productivas de carácter industrial, puesto que dominaba el trabajo artesanal. Al mismo tiempo, la propia idiosincrasia gallega, así como sus condiciones intrínsecas, imponían (e imponen) otras características de la organización tradicional, como la presencia de un sistema de valores de base ideológica o ética (no legal), la escasa división y especialización del trabajo, el ruralismo y la escasa movilidad social. Se trata, en definitiva, de que a la sociedad gallega actual se le propone, desde fuera, como alternativa económica a su sistema de vida predominante (el campo), una opción que, curiosamente, carece de la idea de "progreso" o "avance" que la dinámica social suele tener, puesto que es, en el fondo, un retorno, una vuelta atrás: avanzar o cambiar volviendo al lugar de partida. Para que dicha opción, tan paradójica, pueda resultar aceptable, es obvio que las connotaciones culturales que se le asocian deben cambiar, deben invertir su notación negativa y revestirse de valores positivos en lo económico, lo social, lo económico y lo cultural.

Así, las actividades pertenecientes al sector terciario y vinculadas al turismo, normalmente relacionadas con la hostelería y la restauración, los establecimientos hoteleros y las empresas que ofrecen diferentes opciones para ocupar los momentos de ocio y diversión, resultan novedosas desde el punto de vista laboral para comunidades que, tradicionalmente, se dedicaban a la ganadería y la agricultura, trabajos diametralmente opuestos a los nuevos ámbitos productivos. Sin embargo, no se ha producido sólo un cambio de las tareas desempeñadas o de las formas de realizarlas sino que, para que el sector servicios funcione y sea rentable como actividad económica básica en torno a la cual gire y se desarrolle una comarca, hay que contar ineludiblemente con la presencia de los "otros", forasteros consumidores de esos servicios que durante su actividad turística contactan con la población autóctona. La introducción de la dialéctica entre lo propio y lo ajeno o, para ser más precisos, la coherencia semántica de los términos implicados y el reajuste de sus modelos a un nuevo mundo y a unas necesidades diferentes, es otra característica propia de la actividad social moderna, muy relevante para los estudios antropológicos, dentro del conjunto de cambios que afectan a la que, hasta hace poco, era una sociedad tradicional premoderna, la sociedad gallega, en la que "existía una clara distinción entre los de dentro, y los de fuera" (Giddens 2002: 114). La presencia de los otros no sólo 
fuerza la necesidad de gestionar los productos específicos que se crean para ellos, sino que también obliga a una reflexión sobre lo que cada comunidad quiere transmitir de sí misma y de cómo se ve desde dentro, en una visión emic que, probablemente, no coincide con la que los demás perciben.

En ese juego pseudoespacial y simbólico de identidades entre los que son de dentro y los que son de fuera, se encuentra la actividad turística, en la que no se debe perder de vista que cuanto mayor sea la identificación de la población local con los "productos" que ofrece a los turistas y más consciente sea su inmersión en el proyecto de desarrollo, tanto más altas serán las cotas alcanzadas. Las posibilidades del desarrollo endógeno a través de la potenciación o exaltación de las peculiaridades de cada localidad en el homogéneo abanico global de la oferta turística no sólo emergen por una evaluación externa y positiva de los valores históricos, artísticos, gastronómicos o culturales, tangibles e intangibles, que caracterizan ese lugar. En muchos casos, el mantenimiento y la puesta en valor del patrimonio local funcionan como constructores de la identidad de un territorio a través de la propia elaboración de la experiencia turística que se oferta. En este sentido, el nuevo turismo activo, vinculado a los espacios y a las actividades rurales, constituye un conjunto o pack en el que el continente también forma parte del contenido.

\section{EL MARCO EUROPEO: PAUTAS E INCENTIVOS}

Como hemos dicho con anterioridad, las pautas de este proceso han venido dadas desde organismos supranacionales directamente vinculados a la Unión Europea. En este sentido, consideramos conveniente exponer el marco general en el que se inscriben los cambios experimentados por la sociedad rural gallega en los últimos años.

En líneas generales, la Política Agraria Común (PAC), ha supuesto una de las actuaciones más importantes de todas cuantas lleva a cabo la Unión Europea y, de hecho, el presupuesto del que dispone el FEOGA (Fondo Europeo de Orientación y Garantía Agrícola) para ayudas a las regiones desfavorecidas o a las zonas retrasadas se eleva a cerca de un 50\% del total de los fondos europeos. Sin embargo, y a pesar de su importancia teniendo en cuenta los altos presupuestos que maneja, éste no es el único organismo dentro de la Unión Europea vinculado con el mundo rural. Así, por ejemplo el IFOP (Instrumento Financiero de Orientación de la Pesca) se ocupa de subvencionar todas las acciones vinculadas con la pesca y, de manera más global, el FEDER (Fondo Europeo de Desarrollo Regional) y el FSE (Fondo Social Europeo) suponen complementos muy relevantes en el conjunto de las cantidades aportadas para cada proyecto aprobado, que suele 
contar con diversas vías de financiación europea a las que hay que sumar las procedentes de los ministerios nacionales involucrados en cada caso, las administraciones autonómicas, provinciales y locales para, finalmente, llegar a las aportaciones privadas que puedan realizar algunas personas o empresas interesadas en cada proyecto particular.

Los objetivos de la PAC han ido variando a lo largo de los años desde su fundación en el tratado constitutivo de la entonces Comunidad Europea, pero nuestro interés se centra en los cambios que se produjeron recién iniciada la década de los años noventa del pasado siglo. En aquellos momentos tuvo lugar la creación de las llamadas "medidas complementarias", cuya operatividad más destacada se orientó hacia la puesta en funcionamiento de los sucesivos planes LEADER ${ }^{5}$ (Liaisons entre Activités de Developement de L'Economie Rural), que se iniciaron en 1991 con un plan que duró hasta 1994; en ese año comenzó el Leader II, cuya duración inicial estaba prevista hasta 1999, pero cuyas actuaciones se extendieron hasta finales de 2001, solapándose con su sucesor, el programa Leader Plus, con una duración prevista de seis años, entre 2000 y 2006. Como dato orientativo del nivel de inversión que han supuesto estos planes sucesivos dedicados a apoyar acciones innovadoras de desarrollo rural, podemos recordar que, según los datos de la Comisión Europea, la inversión prevista para el Leader Plus es de 5.046,5 millones de euros.

Sin embargo, la relevancia de todas estas actuaciones no es sólo económica, sino que también resulta muy interesante analizar los cambios de enfoque que han surgido en los últimos tiempos y que se relacionan directamente con una preocupación o toma de conciencia sobre la necesidad de un desarrollo sostenible, ante la imposibilidad de mantener un crecimiento infinito en un planeta que es finito. Así, ha sido precisamente en este último período cuando la Unión Europea ha matizado las pautas que se debían seguir para aumentar las medidas de seguridad de los productos destinados al consumo, la consecución de objetivos medioambientales y la

5 A las actuaciones llevadas a cabo desde la puesta en marcha de los planes Leader hay que sumar las que se acometieron desde el PRODER (Programa Operativo de Desarrollo y Diversificación Económica de Zonas Rurales). El Proder es un programa diseñado y aplicado en España, es decir, de ámbito estatal, coordinado por el Ministerio de Agricultura, Pesca y Alimentación aunque cofinanciado con fondos europeos. Sus líneas básicas de actuación son la valorización del patrimonio rural local con mayor o menor predominio de las actividades agrarias, impulsar el turismo — de manera más concreta el agroturismo- y las pequeñas empresas vinculadas a las artesanías o al sector servicios, así como una revalorización general del sistema agrario y forestal. Al igual que el programa Leader, el Proder se ha secuencializado en tramos: de 1996 a 1999 estuvo en funcionamiento el Proder I y entre 2000 y 2006 el Proder II, que funcionaría como complemento del Leader Plus. 
promoción de una agricultura sostenible, siempre dentro de una política integrada de desarrollo rural en la que la ETE (Estrategia Territorial Europea) apuesta por el establecimiento de una nueva relación entre el campo y la ciudad y la conservación de la naturaleza mediante un desarrollo sostenible y en el que, por primera vez, tiene cabida y se menciona, específicamente, el patrimonio cultural. Los objetivos planteados, pues, en las políticas europeas desde la década de los noventa han dado un giro y en esta última fase ya no están enfocados hacia una producción cuantitativa sino cualitativa. La marca de "calidad" puede abrir una posibilidad de desarrollo vinculado a la explotación de unos recursos, en muchos casos realzados a través del patrimonio, no ya histórico, sino cultural, que además de añadir valor a los bienes de consumo, encaja a la perfección en los atractivos que marcan la diferencia entre distintos territorios, funcionando como reclamo turístico. Es esta una distinción cada vez más necesaria si tenemos en cuenta que: "en la segunda modernidad, donde todos deben situarse en un idéntico espacio global y enfrentarse a exigencias parecidas, la extrañeza ante lo extranjero deja paso a la sorpresa ante lo parecido" (Beck 2000: 133).

En estas circunstancias, desde el sector primario se pueden producir, de manera privilegiada, objetos y mercancías que representen una identidad local específica, sustentados sobre la base de un saber o unas costumbres ancestrales, fuertemente amparadas por una tradición que se interpreta como respetuosa con la naturaleza, nada agresiva con el medio ambiente y productora de alimentos y objetos "naturales" que aseguran la salud, no sólo física, sino también social y, en cierto modo, incluso, moral de la sociedad que los genera. No se trata de que esta tradición sea o no verdad ${ }^{6}$; es más importante que las construcciones sociales que se tejan a su alrededor, creando y recreando una identidad, sean válidas para los individuos que se sienten identificados y se ven reflejados en unos valores atribuidos a su pasa$\mathrm{do}^{7}$, aún reciente y, por lo tanto, en algunos casos vivido. Hablamos, pues, de una identidad y una tradición construida y asimilada, aunque fundamentada en datos objetivos.

Si la globalización es, en gran medida, un fenómeno que extiende la homogeneidad incluso en el tipo de respuestas y resistencias que genera,

\footnotetext{
${ }^{6}$ Cuando hemos hecho referencia a las míticas espirales de clara connotación celta, tampoco se puede afirmar que constituyan una referencia histórica real — grabada en piedra- pero sí que entroncan la cultura gallega con una tradición que la reafirma, conectándola con un estadio mítico compartido.

7 El pasado, la historia, constituye junto a la naturaleza y a la genialidad el lugar común en el que se integran todos los elementos susceptibles de ser patrimonializables, aún cuando lo sean en potencia y no en acto, para lo cual deberán ser activados o puestos en valor (Cf. Prats 1998).
} 
no es menos cierto que los cambios que ha producido han terminado por fortalecer las identidades locales ateniéndose a la continuidad de las relaciones sociales que las sustentan. Ahí está, precisamente, una de las claves para entender por qué ligar el cambio del sector productivo primario al terciario en regiones con un fuerte carácter rural puede ser entendido como una forma de mejoría económica sin devaluar el entramado social y simbólico que caracterizaba a esas sociedades. Como afirma Néstor García Canclini (2000: 26): "El imaginario de un futuro económico próspero que pueden suscitar los procesos de globalización e integración regional es demasiado frágil si no toma en cuenta la unidad o diversidad de lenguas, comportamientos y bienes culturales que dan significado a la continuidad de las relaciones sociales". Efectivamente, el patrimonio cultural activado sirve como puente entre el pasado y el futuro, como entramado referencial para unas sociedades que, como la gallega, están en cambio constante y radical. En la tradición conocemos y reconocemos los valores, no tanto de un pasado, sino del futuro en el que nos proyectamos y, en este sentido, sobre ella construimos el presente. Un presente en el que, por las más diversas razones, el sector turístico, bien gestionado, puede funcionar como solución.

En esta puesta en común de la identidad colectiva local, como construcción social activada desde las instituciones y desde los intereses globales, han tenido una importancia capital la intervención de los Grupos de Acción Local, previstos desde los comienzos de los planes Leader y principales beneficiarios de los mismos, aunque en el Leader II también ha habido otro tipo de interesados, como son los agentes colectivos. Los GAL están constituidos por agentes públicos y privados, asociados para gestionar los fondos que reciben de la Unión Europea. Son los responsables de definir las estrategias que se deben seguir y de seleccionar los proyectos que serán subvencionados, toda vez que, al pertenecer a la localidad en la que se está aplicando el programa, conocen las particularidades y las necesidades para lograr un desarrollo apropiado en ese territorio.

\section{MONDOÑEDO: UN MODELO DE APLICACIÓN}

En este marco referencial vamos a situar un caso concreto en el que, a nuestro entender, se cumplen todas las características que hemos venido exponiendo hasta el momento. Nos referimos a la comarca $^{8}$ de la Mariña

\footnotetext{
${ }^{8}$ El Plan de Comarcalización de Galicia fue puesto en marcha desde la administración autonómica en 1991, y tenía como objetivo reforzar la identidad comarcal y propiciar instrumentos de cohesión interna en unas unidades de actuación que eran ajenas a
} 
Central lucense, una zona incluida entre las clasificadas como Objetivo I por la Unión Europea — al igual que toda Galicia- que abarca $717 \mathrm{Km}^{2}$, situados en el centro de la zona septentrional de la provincia de Lugo, limitando al norte con el mar Cantábrico, al sur con la comarca de la Terra Chá - en ésta se integran los ayuntamientos de Muras, Xermade, Vilalba, Abadín, A Pastoriza, Guitiriz, Begonte, Cospeito y Castro de Rei-, al este con la comarca de la Mariña Oriental —a ella pertenecen los ayuntamientos de Barreiros, A Pontenova, Ribadeo y Trabada-, y al oeste con la Mariña Occidental —integrada por los ayuntamientos de Viveiro, Xove, Cervo, O Vicedo, Ourol y Burela- En ella se combinan, por lo tanto, territorios de interior, flanqueados por la Serra do Xistral y la Serra da Cadeira, bordeando la depresión del valle en el que se encuentra Mondoñedo, capital de la comarca, con la zona de costa abierta al mar. En la comarca, con una altitud máxima que se eleva hasta los mil metros desde el nivel del mar, el clima es oceánico húmedo, con temperaturas suaves y precipitaciones abundantes, lo que favorece las actividades agrícolas, sobre todo en los valles más fértiles, donde las cosechas se duplican en un mismo año, motivo por el cual el sector agrícola es fundamental. En la zona de montaña adquieren mayor importancia, por una parte, la producción forestal, en los últimos años asociada de forma mayoritaria a una especie concreta como es el eucalipto y, por otra, las cabañas de ganado equino cimarrón no estabuladas, que viven en el monte y que una vez al año son saneadas en las conocidas "rapa das bestas". Por su parte, en la zona costera sobresale la actividad pesquera de bajura —aunque sin alcanzar la importancia de otras áreas limítrofes como, por ejemplo, Burela-, y la oferta turística ligada al sol y playa, aún cuando la climatología no se caracterize por garantizar las altas temperaturas.

A la Mariña Central pertenecen ocho municipios: Alfoz, Barreiros, Foz, Lourenzá, Mondoñedo, Riotorto, Trabada y Ferreira do Valadouro, agrupando a un total de población de 28.766 habitantes, que se distribuyen por el territorio con una densidad de cuarenta habitantes por $\mathrm{Km}^{2}$. En esta zona de la provincia de Lugo funciona un Grupo de Acción Local con financiación del plan Leader Plus, la asociación "Terras de Miranda". Tal y como

la mayor parte de la población. De hecho, en la memoria del año 2000, realizada por la Secretaría Xeral de Planificación e Desenvolvemento Comarcal, con motivo del décimo aniversario de la entrada en funcionamiento del plan, el entonces presidente de la Xunta de Galicia, Manuel Fraga, escribía: "Tivemos que traballar para que este país tomase conciencia dun sentimento de pertenza, dunha identificación que ía máis alá —incluso moitas veces se contrapoñía - ó sentimento localista que agroma na pel da nosa sociedade" (SXPDC 2000: 1). La comarca de la Mariña Oriental lucense entró a formar parte del plan diez años después de que comenzase a funcionar; fue aprobada, concretamente, en el Consello de la Xunta de Galicia celebrado el 7 de junio de 2001. 
exige la legislación europea, en la conformación de este GAL "Terras de Miranda" concurren organismos administrativos públicos y entidades privadas de distinto tipo. Así, la forman los ocho ayuntamientos mencionados a los que se suman la Diputación Provincial de Lugo, la Fundación para o Desenvolvemento da Comarca da Mariña Central, el Instituto Lucense de Desarrollo Económico y Social, la Fundación Álvaro Cunqueiro Mora y la Fundación San Salvador, así como prácticamente la totalidad de las asociaciones culturales y deportivas existentes en la comarca, a las que hay que sumar diferentes colectivos, tanto de mujeres rurales como de comerciantes, industriales y autónomos además de diversas empresas y algún particular. Cuando se fundó la asociación "Terras de Miranda" contaba con 54 socios que han ido aumentando hasta llegar a los 81 actuales.

Consideramos importante resaltar el hecho de que, si bien en la constitución de la asociación ha tenido cabida e indudable importancia el sector empresarial, el punto de partida y el germen ha estado en el entramado institucional. En este sentido, reconocemos las palabras de Llorenç Prats cuando afirma que:

quien activa repertorios patrimoniales son en primer lugar los poderes constituidos. El poder político fundamentalmente, los gobiernos locales, regionales, nacionales [...], no tanto porque otros poderes —el poder económico, singularmenteno tengan capacidad para activar repertorios patrimoniales, que la tienen sobrada, sino porque, en general, están escasamente interesados en proponer versiones de una determinada identidad (Prats 1998: 68).

Y más aún cuando en una publicación reciente, el mismo autor matiza: "he sostenido y continúo sosteniendo que los procesos de activación del patrimonio dependen fundamentalmente de los poderes políticos. Sin embargo, estos poderes deben negociar con otros poderes fácticos y con la propia sociedad" (Prats 2005: 19). Esto es lo que está ocurriendo realmente en el funcionamiento de los Grupos de Acción Local promovidos desde los planes europeos: una búsqueda consensuada de las estrategias que se deben seguir para conseguir el desarrollo de cada territorio de manera endógena, por dentro. Es cierto que siguen unas directrices que vienen eminentemente pautadas por el poder político, pero ya desde el mismo momento de su constitución pretenden contar con la aprobación de los restantes poderes para, finalmente, alcanzar el beneplácito de la sociedad.

El nombre elegido para la asociación constituye la primera particularidad de este proyecto, puesto que es una apropiación de un espacio fantástico en el que se ubica la trama de una obra literaria?. Álvaro Cunqueiro,

\footnotetext{
9 Debemos puntualizar que, en la misma línea, el Ayuntamiento de Mondoñedo señalizó, en 2001, determinados lugares destacados de la localidad bajo el lema "Mil pri-
} 
escritor nacido en Mondoñedo, publicó en 1955 su primera obra narrativa en gallego, titulada Merlín e familia ${ }^{10}$, ambientada en un lugar inexistente en la geografía física de la zona pero con un nombre abundante en la toponimia real y física pero también simbólica de la cultura gallega: o $l u$ gar de miranda ${ }^{11}$. "Terras de Miranda" ha sido la opción elegida para denominar al Grupo de Acción Local que representa no sólo al Ayuntamiento de Mondoñedo ${ }^{12}$, sino a toda la comarca; un topónimo ficticio en la zona pero entroncado con la tradición popular y vinculado a la literatura y, por lo tanto, a la cultura ilustrada; toda una marca de identificación social refrendada

maveras máis", extraído también de una cita de Álvaro Cunqueiro, en la que el escritor hacía referencia a lo que podría ser su propio epitafio y a propósito de la utilización de la lengua gallega en su obra. El texto completo de la cita es el siguiente: "Eu quixen e quero que a fala galega durase e continuase, porque a duración da fala é a única posibilidade de que nós duremos como pobo. Eu quixen que Galicia continuase e, ao lado da patria terrenal, da patria que son a terra e os mortos, haxa estoutra patria que é a fala nosa. Se de min algún día, despois de morto, se quixese facer un eloxio, e eu estivese dando herba na terra nosa, podería dicir a miña lápida: "aquí xace alguén que coa súa obra fixo que Galicia durase mil primaveras máis”".

${ }^{10}$ La leyenda del mago Merlín está indisolublemente ligada al Santo Grial, que entronca con una tradición simbólica, propia de la Edad Media y tiene un importante calado en la cultura popular gallega, que identifica el cáliz del Cebreiro - puerta de entrada en Galicia del Camino de Santiago francés- con el utilizado por Cristo en la Última Cena. Este personaje, que aparece retirado a las Terras de Miranda en su vejez, es el protagonista de la novela fantástica que Cunqueiro pone en voz de Felipe de Amancia, criado de Merlín y que narra las historias de los personajes que acudían a la casa del mago, así como los hechos que le acontecían a él mismo mientras cumplía, fuera, los encargos que le eran encomendados por su amo. Desde un punto de vista histórico, Mondoñedo fue capital de la provincia de Bretoña hasta la eliminación formal del Reino de Galicia en 1833.

${ }^{11}$ En la tradición oral gallega es habitual jugar con los topónimos Miranda o Mirandela con el hecho de no hacer nada, de estar mirando: "iqué bonito é o lugar de miranda!". Esta situación se presenta como un descanso frente a la actividad laboral cotidiana que en la sociedad rural era continua, con una mínima salvedad los domingos y los días festivos en los que, a pesar de estar limitada la realización de algunos trabajos, sí había que cumplir con determinadas ocupaciones insalvables. El hecho de que el Merlín de Cunqueiro aparezca "retirado" a Miranda podría asociarse a esa evocación de no estar en activo, al hecho de la propia distancia física de Mondoñedo con el lugar originario del mago y, también, a la percepción de que el que mira siempre ve algo y de que siempre hay alguien mirando que puede ver.

${ }^{12}$ Sin embargo, la identificación entre Terras de Miranda y Mondoñedo es inmediata en la actualidad. Sirva como ejemplo una serie de televisión rodada en 2001, coproducida por TVG, Voz Audiovisual y Zopilote, dirigida por Xurxo Coira y que llevaba por título Terras de Miranda, cuyos exteriores se rodaron en Mondoñedo, y que fue concebida como una representación del prototipo social y natural de la Galicia interior. 
ahora desde un punto de vista institucional. En esta elección ha predominado, pues, la función connotativa del lenguaje frente a la función denotativa que caracteriza a otros grupos de acción local que funcionan en Galicia en la actualidad, como pueden ser "Eume", "Monterrei-Verín", "Ordes", "Terra Chá" o "Terras do Miño", entre otros, y que se identifican con un topónimo geográfico.

Además, "Terras de Miranda" podría adscribirse sin problemas a la categoría de las nomenclaturas que incorporan el formato de eslogan publicitario; es decir, un enunciado breve que sirve para definir o identificar el producto y que el receptor relaciona inmediatamente con el mismo, aún cuando las connotaciones del lema y lo que se pretende vender sean cuestiones más o menos lejanas. En todo caso, el eslogan combina un mensaje original, expresado de forma breve y que además resulta sugerente y atractivo, en el que "su función pasa más por corporativa que por acción publicitaria" (Fernández Gómez 2005: 101).

El hecho de que la denominación haya sido una elección connotativa refleja, entre otras cosas, una aspiración, lo que se quiere ser o promocionar. Se opta por una posibilidad entre otras porque representa algo con lo que la comunidad se identifica a sí misma y que, al mismo tiempo, se presenta como una etiqueta para que los otros, los turistas, los foráneos, la identifiquen desde fuera. Además, incorpora otras cuestiones nada irrelevantes como son: un componente mítico que invita a la fantasía y un referente culto literario que además apela a la identidad gallega en cuanto construcción simbólica popular. No es menos cierto que la elección también supone una denominación eufemística "inocua" para la figuración exclusiva de un nombre que aglutine varias localidades sin que prevalezca ninguna -las "Terras de Miranda" pueden estar en cualquier parte aunque, eso sí, próximas a Mondoñedo- Por último, no podemos obviar el aprovechamiento de un recurso cultural local que ya existía y que aseguraba la repercusión y la trascendencia de cara al exterior, toda vez que el creador original de la idea había nacido en ese lugar pero su proyección como exponente de las letras y de la cultura gallega es indiscutible y refrenda o avala la denominación como si se tratase de una marca que garantizase, tanto la originalidad, como la relevancia y el reconocimiento ya conseguido. Lo que se ha producido, pues, no es una creación, sino una utilización del término para unos fines claramente orientados más allá del objetivo del programa que requería de esa denominación. "Terras de Miranda" es una seña de identidad propia en la que se reconoce la comarca y que también funciona para publicitarse hacia fuera.

Las actuaciones llevadas a cabo por la asociación "Terras de Miranda" han sido varias, pero nuestro interés se centra en las realizadas en torno a 
la puesta en valor del patrimonio cultural y arquitectónico en la comarca que, en este caso, han sido cuatro. En primer lugar, diferentes actuaciones de recuperación de un mazo y su entorno en el Ayuntamiento de Riotorto, que recibieron una ayuda de 181.252,75 euros, de los 213.238,52 euros a los que se elevaba el presupuesto; también una actuación arqueológica en el castro de Zoñán, perteneciente al Ayuntamiento de Mondoñedo, para la que se destinaron 109.026,62 euros, frente a los 128.266,63 euros de inversión total; en tercer lugar la promoción y valorización de oficios y productos artesanales en el Barrio dos Muíños de Mondoñedo, con una ayuda de 49.055,73 euros de los 57.028,28 presupuestados y, finalmente, la divulgación de los trabajos arqueológicos realizados en el Castro de Zoñán, que ha supuesto un gasto mucho más reducido, ya que sólo se han invertido 4.640,00 euros de los cuales 3.944,00 constituyeron la ayuda recibida. En todos los casos el tanto por ciento de las inversiones que ha sido subvencionado se corresponde con un $85 \%$, con la única excepción de la promoción y puesta en valor de los oficios y productos artesanales, en que ascendió de manera casi inapreciable hasta alcanzar el 86,02\%. Consideramos significativo resaltar aquí que, pese a lo elevado que resulta el porcentaje de ayudas recibidas, ninguna de las propuestas ha sido clasificada en la categoría de productiva, ya que no se desprendía de esas actuaciones una rentabilidad manifiesta.

Dos de los cuatro proyectos podrían considerarse, en realidad, como partes sucesivas y lógicas del desarrollo de una única idea. Es el caso de las actuaciones arqueológicas en el Castro de Zoñán, en las que, a una primera fase prospectiva, siguió la publicación de los resultados obtenidos. Estas dos actuaciones, que podemos considerar en conjunto, ya han sido ejecutadas y han certificado el cien por cien de la contabilidad. Con ellas se pretende investigar y divulgar una sección concreta del patrimonio vinculada a los estudios arqueológicos ${ }^{13}$ con un matiz claramente histórico que siempre ha tenido un reconocimiento explícito de su valor en función de la antigüedad que atestigua.

Por lo que respecta al proyecto del Ayuntamiento de Riotorto, es el más importante desde el punto de vista de la cuantía económica invertida y se encuentra todavía en una fase inicial, con sólo un 19,12\% de los gastos certificados. Por su parte, la promoción y valorización de oficios y produc-

${ }^{13}$ En el Título V de la Ley 16/1985, de 25 de junio, del Patrimonio Histórico Español, se recoge que "forman parte del Patrimonio Histórico Español los bienes muebles o inmuebles de carácter histórico, susceptibles de ser estudiados con metodología arqueológica, hayan sido o no extraídos y tanto si se encuentran en la superficie o en el subsuelo, en el mar territorial o en la plataforma continental" (Castro Allegue 2005: 75). 
tos artesanales está, también, prácticamente ejecutada y ya ha certificado un 89,03\% del presupuesto. Estos dos proyectos están relacionados con el patrimonio etnográfico en una doble vertiente; en primer lugar con la faceta más tangible y material que incluye las edificaciones y los objetos vinculados a las actividades laborales, estéticas y lúdicas de cualquier grupo humano. En segundo lugar, también con la más sutil e inmaterial, que afecta al reconocimiento del valor de conocimientos o actividades relacionados con técnicas y saberes tradicionales utilizadas por una comunidad determinada. Es decir, no sólo tienen valor los objetos producidos, sino también las diferentes formas de producir esos objetos y los conocimientos a ellos ligados. Esta doble vía supone una duplicación de las posibilidades que ofrece el patrimonio etnográfico a la hora de ser utilizado como recurso de desarrollo local amparado en los atractivos turísticos, porque no sólo se ofrece el producto sino también el proceso, de manera combinada, complementarios el uno del otro pero diferenciados.

Hemos remarcado la diferenciación entre las propuestas aprobadas por el GAL constituido en la asociación "Terras de Miranda”, porque si bien es cierto que las cuatro forman parte indiscutible del patrimonio cultural, también lo es que parten de dos compartimentos distintos que se relacionan, a su vez, con dos disciplinas diferentes: la arqueología y la antropología. Dentro de la segunda, a partir de ahora, nos centraremos en la descripción y el análisis de la promoción y valorización de oficios y productos artesanales en el Barrio dos Muíños de Mondoñedo, no sólo porque se ubica en la capitalidad de la comarca, sino porque presenta un nivel de ejecución mayor y, posiblemente, una aglutinación de intereses más elevada. Así, esta actuación, que, como hemos reseñado, parte de una asociación que constituye un grupo de acción local promovido desde instancias europeas, estatales y autonómicas con la ejecución de los planes Leader y Proder, también es el objetivo final de un entramado más complejo que intentaremos describir.

\section{PONER EN VALOR LA TRADICIÓN: UNA APUESTA DE FUTURO}

Para poder entender el proyecto de manera integral es necesario hacer una pequeña localización geográfica y una somera revisión histórica de la ciudad y del propio barrio en el que se plantea llevar a cabo. Mondoñedo es una ciudad situada, como ya hemos mencionado, en la comarca de la Mariña Central lucense, en una zona de interior pero muy próxima ya a la línea de costa; fue una de las siete capitales del antiguo Reino de Galicia ${ }^{14}$

${ }^{14}$ El Reino de Galicia es una entidad política que surge en el siglo x y se mantiene, por lo menos de manera nominal, hasta el año 1833, cuando se instaura una división 
y, como tal, centro neurálgico del poder político, económico y social de toda la comarca. Además, la ciudad, que fue declarada Conjunto Histórico Artístico en 1985, es todavía hoy sede episcopal de la diócesis Mondoñedo-Ferrol y en ella están ubicadas tanto la Catedral, del siglo XIII —construida en estilo cisterciense y declarada Monumento Nacional en el año 1902- como el que fue el primer seminario de Galicia, que data del siglo Xvi. Su elevado rango como cabecera administrativa y burocrática, tanto en cuestiones laicas como religiosas, hizo que Mondoñedo siempre ejerciese una fuerza centrípeta sobre la comarca, funcionando como un polo de atracción para los movimientos de la población más o menos próxima. Junto a ello, la existencia de un más que destacado patrimonio histórico-artístico, ligado precisamente a su importancia desde el punto de vista eclesiástico, que se complementa, en menor grado, con lo civil, le otorgó un cierto abolengo que siempre acaparó el interés turístico, sobre todo en determinadas épocas estivales. Esta entidad, de enclave histórico-artístico que atraía a numeroso público, se vio considerablemente reforzada por una cuestión geográfica y climatológica, ya que Mondoñedo, desde siempre, se presentó como un lugar digno de ser visitado como alternativa cultural a la no siempre soleada ni cálida costa lucense. En una oferta turística pasiva donde imperaba la propuesta de sol y playa, Mondoñedo era el recurso cultural en su vertiente histórico-artística, favorecido, además, por su proximidad geográfica al lugar de veraneo, para los días nublados o incluso lluviosos que existen en el clima del norte peninsular, incluso en verano.

Este turismo, que podríamos calificar entre los de corta duración e impregnado por un fuerte carácter estival, puesto que un día de visita, preferentemente de verano, resulta suficiente cuando la oferta se limita a observar la riqueza monumental de la ciudad, refrendada desde las instituciones con la concesión de menciones específicas, ha estado presente en Mondoñedo durante mucho tiempo y constituye, también en la actualidad, una de las posibles ofertas turísticas. De hecho, son muy numerosas las excursiones programadas que incluyen una parada y la correspondiente visita a la ciudad en diferentes momentos del año y, muy especialmente coincidiendo con celebraciones primaverales como las típicas "rapas das bestas", o con festividades como "As San Lucas", que se celebran a mediados de octubre y que están consideradas, junto con el "San Froilán", como reminiscencia de las importantes ferias otoñales existentes hasta no hace tantos años en la provincia de Lugo.

político-administrativa basada en el modelo de departamentos francés, que reduce a cuatro el número de provincias. Mientras duró el Reino de Galicia estuvo formado por siete capitales: A Coruña, Betanzos, Santiago, Lugo, Mondoñedo, Ourense y Tui. 
La vinculación de Mondoñedo y la actividad turística era la que acabamos de exponer hasta que, desde el Ayuntamiento, integrado en la asociación "Terras de Miranda", se plantea iniciar en el verano del año 2003 el proyecto Artesanía Os Muiños. Esta propuesta "busca a potenciación do barrio e a dinamización turística de Mondoñedo, ampliando a oferta e, con eso, o atractivo deste concello, apostando, sempre e en todo momento, pola calidade", según consta en el folleto informativo que se elabora desde el propio Ayuntamiento para su presentación pública. Esta intervención formaba parte de un complejo entramado cuyo origen hay que buscarlo en el programa de Rebabilitación de Vivenda Rural que, desde 1987 pone en marcha el Instituto Galego da Vivenda e Solo ${ }^{15}$, dependiente de la Consellería da Vivenda e Solo de la Xunta de Galicia. Pues bien, dentro de este programa se promueve, ya a finales de la década de los 90, la rehabilitación de varias casas y el acondicionamiento de zonas públicas en la ciudad de Mondoñedo y, más concretamente, en el Barrio dos Muíños.

Este barrio está situado en una zona muy próxima al centro de la ciudad, la plaza de la Catedral y dentro del casco histórico, pero en contacto total con el mundo rural, lo que justificaría su inserción en el programa de rehabilitación de viviendas rurales. De hecho, el Barrio dos Muíños era, hasta hace poco tiempo — finales de los años 70-, lugar de residencia de una población que compaginaba el ejercicio de las tareas agrícolas, en pequeñas huertas colindantes con sus viviendas, con actividades proletarias o artesanales. Sin embargo, siguiendo la pauta del resto de la ciudad, en los últimos años el barrio no ha dejado de perder población, al mismo tiempo que se ha producido un progresivo envejecimiento.

Las actuaciones que lleva a cabo el IGVS en el barrio se programan en dos fases sucesivas que preveían la recuperación y construcción de un total de 40 viviendas para jóvenes -15 en la primera fase, como experiencia piloto, y 25 en la segunda fase- que, una vez habilitadas, serían concedidas en régimen de alquiler durante tres años, existiendo, al cabo de estos, la posibilidad de compra por parte de los, hasta entonces, arrendatarios. De consumarse esta opción, a los nuevos propietarios se les descontarían del precio final de la vivienda las cantidades ya abonadas como alquiler durante ese primer período. Esta oferta estaba pensada para facilitar el acceso a la vivienda a jóvenes menores de treinta y cinco años, con lo que se pretendía buscar una solución a la dificultad que este colectivo tiene para conseguir un primer lugar de residencia, facilitando el tránsito mediante ese

15 El IGVS ha sido, por tanto, el origen de las intervenciones desde la administración pública en la transformación del espacio físico en el que se ubica el proyecto "Artesanía Os Muíños". 
régimen inicial de alquiler que revertiría en los beneficiarios y que, sin duda, aminora el importante desembolso inicial que supone comprar una casa. Además, también se pretendía atajar otras cuestiones, como la degradación de un barrio integrado en el casco urbano ante el abandono paulatino de la población, mediante la fijación de población joven que asegurase, de alguna manera, el futuro, por lo menos a medio plazo.

En la ejecución de la primera fase se rehabilitaron ocho viviendas y se construyeron otras cinco nuevas como solución a determinados problemas técnicos de ejecución de las obras que, en algunos casos, implicaron el derribo total de las edificaciones existentes ante la imposibilidad de recuperación. Estas trece viviendas, que terminaron por conformar la primera fase, ya fueron adjudicadas. La segunda fase de ejecución quedó paralizada desde el cambio que se produjo en el gobierno autonómico y que llevó a la presidencia de la Xunta al PSOE en coalición con el Bloque Nacionalista Galego. En este punto, consideramos conveniente matizar que tanto la Deputación Provincial de Lugo — impulsora de los programas Leader en toda la provincia- como el Ayuntamiento de Mondoñedo estaban en ese momento gobernados por el Partido Popular, mientras que la Consellería de Vivenda e Solo, encargada de la rehabilitación del barrio, pasaba a estar dirigida por el PSOE, y la otra consellería implicada, la de Industria, dependía del Bloque Nacionalista Galego.

En todo caso, al margen de las cuestiones políticas, cuando la primera fase del plan de rehabilitación inmobiliaria ya estaba ejecutada por los anteriores responsables de la citada consellería es cuando surge el proyecto de recuperación de las artesanías proyectado con la colaboración de la Deputación Provincial de Lugo, el Instituto Galego de Vivenda e Solo, la Consellería de Industria y el Concello de Mondoñedo y que ha contado, además, con la financiación de los planes europeos a través de la Asociación "Terras de Miranda". En esta propuesta se enlazarían dos posibilidades complementarias: por una parte, dar a las actuaciones urbanísticas, llevadas a cabo en la zona, una salida comercial, gracias a los espacios rehabilitados y, por la otra, aumentar la oferta turística ya existente, muy vinculada y limitada al centro histórico, recogiendo, además, las nuevas pautas de orientación del turismo hacia productos de calidad vinculados con el mundo natural y la tradición cultural.

Artesanía Os Muiños fue presentada a la prensa y al público en general estructurada también en dos fases de ejecución. Unos meses antes del verano de 2003, el alcalde presentó el plan de actuaciones previsto junto a tres artesanos - una alfarera, un zoqueiro y un molinero- que firman ese mismo día un convenio por el que, los dos primeros —instalados hasta entonces en los ayuntamientos de Foz y Alfoz, respectivamente- acceden 
a ocupar los locales correspondientes en el Barrio dos Muíños, mientras que el tercero no modificará su ubicación, teniendo en cuenta las dificultades que presenta el traslado de un molino que estaba todavía en funcionamiento. Esta propuesta se complementaría con otras actividades lúdicas de carácter estacional que, como proyecto, se limitan a paseos en pony por el barrio durante el verano. En esa misma presentación, para el año 2004 se propone la ejecución de la segunda fase, que en realidad es una ampliación de la primera, añadiendo a los talleres-museo otros oficios artesanales como la cestería, la forja y el tejido.

Así, por primera vez se recurre al patrimonio cultural relacionado con las artesanías, como posibilidad para promover el desarrollo local de cara a los turistas. De esta forma, la propuesta clásica, basada en la indiscutible monumentalidad arquitectónica de la ciudad - con un importante valor tanto artístico como histórico-, reconocida desde una élite ilustrada, aunque minoritaria, y refrendada mediante declaraciones formales por parte de diferentes instituciones, se complementa con un patrimonio tangible e inmaterial asentado en la tradición, perteneciente también a la historia pero, en este caso, a la historia de la vida cotidiana, a la historia con minúsculas.

Los artesanos que suscribieron el acuerdo se instalaron en el barrio permitiendo que los turistas accediesen a los talleres mientras realizaban su trabajo, convertidos en pequeños museos, tanto de los objetos producidos, que se exponen para su venta, como del proceso. Aceptaron comprometerse, pues, en una labor didáctica, atendiendo al público, explicándole sus conocimientos y realizando demostraciones. A cambio, disponen de los locales acondicionados para el desempeño de su actividad y reciben asesoramiento legal y burocrático, así como el respaldo institucional y la promoción de sus establecimientos. De hecho, la inversión realizada por "Terras de Miranda" en la promoción y valorización de oficios y productos artesanales, que ascendía a 49.055,73 euros, está calificada como no productiva porque se limitó a cuestiones publicitarias y promocionales - por ejemplo, entre otras, los paneles informativos sobre los oficios que decoran los talleresmuseo- aún cuando, evidentemente, lo que se publicita son actividades y productos con rentabilidad comercial. En períodos de menor afluencia de visitantes, los artesanos pueden disponer de otras fórmulas para completar sus ingresos; por ejemplo, la impartición de cursillos de aprendizaje de los respectivos oficios, asegurando, de algún modo, la continuidad del conocimiento tradicional y una recuperación más eficiente. Esta opción está dirigida fundamentalmente a niños y jóvenes en edad escolar, dependientes del sistema educativo, con lo que supone también la inserción, aunque relativa e indirecta, de los artesanos en el aparato institucional como "docentes", con el respaldo que eso implica para su consideración social dentro de la pro- 
pia comunidad. Por otro lado, desde un punto de vista didáctico, no cabe duda de que la entrada en el sistema escolar de estos contenidos artesanales ha de servir para afianzar la vinculación de las futuras generaciones con los mismos, repercutiendo también en su consideración social.

Los talleres que actualmente están funcionando en el barrio son los de alfarería, zuecos, fotografía, títeres y una pastelería, a los que hay que añadir el molino. Todas estas actividades se presentan bajo una misma denominación de artesanales y se vinculan al pasado y a la tradición del lugar en el que ahora se ofertan, independientemente de que esto sea cierto o no ${ }^{16}$. De hecho, la veracidad no es un fin perseguido en este tipo de actuaciones y más teniendo en cuenta que cualquier sociedad "modifica sus recuerdos para reajustarlos con las condiciones variables de su equilibrio" (Halbwachs 2004: 336). Para ellos se ha creado lo que Ballart Hernández y Juan i Tresserras (2001: 206) denominan "la imagen de marca", vinculada con claridad meridiana al espacio en el que se exponen, la "Artesanía dos Muíños" en el Barrio dos Muíños ${ }^{17}$; y a la autenticidad que se ve refrendada, además, por un entorno rural en el que se aprecian varias connotaciones que avalan los productos — realizados a mano-y las actividades allí desarrolladas.

Ya hemos mencionado que el Barrio dos Muíños se encuentra próximo al casco histórico pero en el límite de la ciudad; después de él no hay más edificaciones urbanas y la mayor parte de las viviendas que lo conforman son casas unifamiliares con un espacio anexo o, en el peor de los casos, muy próximo, dedicado a huerta para autoconsumo. El barrio está atravesado por varias corrientes de agua canalizadas para el aprovechamiento de la fuerza hidráulica del río Valiñadares en diferentes molinos que antaño funcionaban en la zona y que dan nombre al barrio. Precisamente sobre este río se encuentra la Ponte do Pasatempo ${ }^{18}$, un lugar muy interesante para ser

16 Para autores como Francisco Cruces (1998: 86): "en cierta manera todo patrimonio es a la vez auténtico e inauténtico, puesto que se trata de un sistema de representaciones. Como tal está dotado, por definición, de un buen grado de convencionalismo y teatralidad".

17 Véase la página web: http://www.artesaniaosmuinos.com/

18 La Ponte do Pasatempo debe su nombre a los acontecimientos acaecidos en 1483 dentro del denominado proceso de doma y castración del Reino de Galicia. Allí fue donde los enviados del Obispo de Mondoñedo entretuvieron a Isabel de Castro, perteneciente a la poderosa Casa de Lemos por nacimiento, casada con el Mariscal Pardo de Cela Aguiar e Ribadeneyra, sobrina del Obispo de Mondoñedo y prima de la Reina Isabel la Católica a quien, precisamente, recurre para solicitar un indulto cuando su esposo y su hijo son condenados a muerte dentro de la guerra desatada, por mantener sus privilegios, entre la nobleza gallega y la castellana tras la muerte de Enrique IV de Castilla. Según la leyenda, el indulto conseguido no llegó a tiempo por esa interceptación a la entrada 
puesto en valor como atractivo turístico y que incide en las posibilidades del barrio. En general, este entorno favorece la patrimonialización de las actividades artesanales y de los productos resultantes en tanto forman parte de un estado "natural" de las cosas que atrae a los sujetos interesados por lo considerado como verdadero, aquello a lo que no se le atribuyen artificios ni mezclas y que nos acerca al bienestar frente a la modificada y manipulada vida moderna -incluidos los alimentos_, de la que los consumidores de turismo cultural se evaden durante sus viajes más o menos prolongados.

Esta naturaleza domesticada por el hombre que conforma el paisaje y la arquitectura del barrio tiene, además, en sus cercanías, la otra cara de la moneda, la naturaleza salvaje, abrupta, indomable y misteriosa que también constituye un elemento de alto interés patrimonial. Nos referimos a las Covas do Rei Cintolo, a las que se accede desde el Barrio dos Muíños y que consisten en un afloramiento calcáreo situado en el macizo calizo de Mondoñedo. La cueva del Rei Cintolo es la más importante de todas las que existen en esta formación natural con más de 6.500 ms. explorados que llegan en su mayor cota de profundidad a los $75 \mathrm{~ms}$. Al margen de las cuestiones científicas, cuyo debate sigue abierto, la cueva constituye un atractivo turístico como fenómeno natural para los interesados, por ejemplo, en la espeleología pero, también, para el público en general, porque en ella se mezclan las caprichosas formas perennes de la naturaleza con el pasado ancestral del ser humano, ya que se han encontrado restos de un individuo datados a finales del Paleolítico Superior. En este caso, el patrimonio natural se conjuga con el patrimonio cultural por la presencia mítica del hombre desde tiempos tan remotos y le otorga a ese espacio unas connotaciones espirituales y simbólicas de gran trascendencia social, certificadas, como no podía ser menos, con una leyenda, según la cual en la cueva habita la bella princesa Manfada, hija del Rei Cintolo, presa de un conjuro de amor por el cual el gran castillo en el que vivía fue tragado por la tierra dando origen a las cuevas.

Precisamente en el interior de la cueva de mayor tamaño, Carlos Núñez, uno de los músicos gallegos con mayor proyección internacional, ha grabado uno de los temas de su disco Almas de Fisterra $^{19}$ que lleva por título As

de la ciudad y el Mariscal fue decapitado en la Plaza de la Catedral. Con su muerte el Mariscal Pardo de Cela pasó a convertirse en símbolo de la resistencia gallega contra el poder foráneo, creándose un mito en torno a su figura que nada tiene que ver con su cruel comportamiento en las Revueltas Irmandiñas contra el campesinado gallego para evitar perder sus privilegios.

19 En el título queda patente el referente espiritual que este lugar geográfico supone para los gallegos y que los conecta con otras culturas periféricas atlánticas, conformando la cultura celta. 
Covas do Rei Cintolo. El hecho de que Carlos Núñez sea un gaiteiro reconocido en todo el mundo folk y muy relacionado con la música bretona, irlandesa y, en general, con la música tradicional ${ }^{20}$, ha ayudado a vincular ese espacio natural con las entrañas de un espacio referencial mítico gallego aprovechando, al mismo tiempo, las connotaciones de raigambre céltica de las que participa, de forma generalizada, la cultura gallega contemporánea. En esta misma línea, Rei Zentolo es una empresa gallega que nació, también, en el año 2003 y que se dedica a la producción de los más variados objetos en los que recrean lo que denominan "arte popular autóctona" muy vinculada con la tradición. Sus productos portan lemas y refranes de la cultura popular gallega traducidos al inglés o la adaptación de imágenes gallegas a referentes de la cultura anglosajona. Por ejemplo, es muy conocida su imagen de la escritora Rosalía de Castro $^{21}$ en el estilo pop-art con el que Andy Warhol retrató a Marilyn Monroe.

El aprovechamiento de las cuevas como recurso patrimonializable de cara al turismo y vinculadas al Barrio dos Muíños estaba también incluido en el proyecto Artesanía Os Muiños o, mejor dicho, la recuperación de la artesanía se vinculó, en el catálogo promocional al que ya nos hemos referido, a un "plan xeral de dinamización turística que se está a desenrolar no concello de Mondoñedo, no que se inclúen, entre outros elementos, a habilitación para o turismo dunha parte da cova do Rei Cintolo". Esta actuación, que finalmente se puso en funcionamiento en la primavera de 2006 fue paralizada en el mes de noviembre de ese mismo año por orden judicial, después de que la Federación Gallega de Espeleología denunciase los posibles daños que las visitas turísticas podían ocasionar al interior de la cavidad. Este colectivo tiene, además, otra causa judicial anterior abierta contra la Diputación Provincial por la licitación de las obras de acondicionamiento en el interior de las grutas, previas a su apertura al público. Con motivo de la suspensión cautelar de las visitas guiadas, en el pueblo se organizó una manifestación de vecinos el día 11 de noviembre de 2006 contra la medida judicial en la que intervenieron también colectivos hosteleros y comerciantes, así como todos los partidos políticos, tanto el PP, que ejerce el gobierno, como el PSOE y el Bloque desde la oposición. En el manifiesto leído ese día se hacía mención a "unha Cova do Rei Cintolo en pleno desenrolo turístico, en beneficio de todo e, moi especialmente de

\footnotetext{
${ }^{20}$ Ha colaborado, por ejemplo, con la cantante portuguesa Dulce Pontes.

${ }^{21}$ Rosalía de Castro está directamente relacionada con el nacionalismo gallego; tanto por los temas tratados en su producción literaria como por su recuperación del gallego como lengua literaria. Además, estuvo casada con Manuel Murguía, uno de los padres de la historiografía gallega.
} 
Mondoñedo". Vemos, pues, que la idea de asumir el patrimonio que se ofrece hacia fuera como un bien de desarrollo endógeno y, por lo tanto, su asunción como algo propio sí ha funcionado, al menos en lo que se refiere al espacio natural de las cuevas, llegando a la movilización en bloque de las fuerzas políticas, los comerciantes y los vecinos de la ciudad.

\section{CONCLUSIÓN (RE)CREANDO LA DIFERENCIA}

Si recapitulamos las circunstancias expuestas hasta el momento en el proceso de recuperación y rehabilitación del Barrio dos Muiños mindoniense, podemos apreciar un proceso integral e integrado que deriva de una concurrencia de fuerzas y de elementos, algunos de ellos heterogéneos, que forman, como conjunto, una unidad simbólica, fundamentada en ciertos esquemas míticos, de interpretación y designación de esa misma realidad, tanto en un sentido externo como interno, para los foráneos y para los propios.

Así, comprobamos que, por un lado, existe un aprovechamiento del sistema tradicional, o lo que pudiera quedar de él, refundido y versionado en cuanto a su sentido y a sus formas de representación más relevantes, en la dirección de lo que, en el estado de cosas actual, se considera que este mundo tradicional debería ser. Permanencia, pues, pero con las adaptaciones necesarias, a las que ya nos hemos referido, para que, al menos en una dimensión simbólica identitaria, aunque no en su existir real y cotidiano, se pueda decir que lo tradicional ha encontrado una forma de expresión en el mundo actual.

Por otro lado, es obvio que se puede percibir el proceso de generación de un nuevo sistema de valores y de relaciones que responde a la definición misma del concepto de sistema; es decir, se origina un conjunto de elementos nuevos y una red de significados que va a actuar entre ellos. En este caso, se produce un marco de referencias en el que diversos factores co-presentes interactúan para dar lugar a una red de nuevos significados interferidos mutuamente y, también, retroalimentados en cuanto a sus valores. Partiendo de esta circunstancia, podemos considerar que el Barrio dos Muiños es, en sí, sólo uno de estos elementos mencionados anteriormente y que se va perfilando, en cuanto a valor cultural susceptible de entrar en el mercado turístico a través de la creación de una "personalidad de marca" (Verdés Vilaseca 2000: 358).

En primer lugar, hemos mencionado el entorno patrimonial, tanto histórico como cultural, reconocido de manera institucional desde hace años, como hemos visto, y que actúa como primer punto de reclamo turístico. Hablamos, sin embargo, de un tipo de turismo relativamente "especializado", unido a los contenidos culturales del patrimonio artístico de carácter 
oficial y que, en principio, no ofrece el mismo tipo de objetos de consumo o de atractivos que lo que se puede llamar, genéricamente, la cultura popular y que es, justamente, la que se ve implicada en el proceso de recuperación al que nos estamos refiriendo. El patrimonio cultural institucionalizado exige más actividades turísticas de naturaleza estática, por ser él, en sí mismo, una entidad invariable sobre la que hay que actuar, en cuanto a su aprovechamiento turístico, mediante la conservación o promoción. Se espera, al acudir a este tipo de reclamo, un correcto estado de conservación de los objetos que forman parte del patrimonio, unos fondos de cierta entidad o relevancia y una suficiente accesibilidad. En cambio, cuando hablamos de patrimonio cultural de origen popular — ciertamente institucionalizado también en los últimos años- podemos, en primer lugar, llegar a la bifurcación que diferencia lo material de lo inmaterial, ambos contenidos en este concepto, tal y como la propia legislación reconoce. En segundo lugar, este mundo, al que pertenecen por derecho propio las artesanías, no se concibe sin la actividad, ajenos, pues, al estatismo de la cultura material oficial. Queremos decir, con ello, que se trata de una realidad en continua realización, concebida como una suerte de energeia en la que el proceso es tanto o más importante que los objetos producidos. No basta con conservar las piezas en un museo, aunque sea un museo ad boc; éstas, como representación simbólica de la identidad colectiva, están insertas en el decurso vital del grupo humano que las produce y, por tanto, su valoración no se hará en función de su relevancia artística - como en el caso anterior-, sino, sobre todo, a partir de su representatividad, de su función metonímica. Así, mantener su producción, aunque sea desde una recuperación de la misma, equivale a mantener la cohesión grupal, recreándola como algo que no ha roto con los orígenes y que se proyecta hacia el futuro.

Es en estas coordenadas donde podemos explicar el funcionamiento de los diferentes talleres que se distribuyeron por el Barrio dos Muiños, entendidos como pequeños eco-museos en los que no sólo se atesoran las piezas del pasado, sino también se da cabida a la producción actual —en la que se valora la originalidad artística de cada pieza pero vinculada por contigüidad al pasado, sin cuyo discurso carecería de valor intrínseco- y a su proceso, en el que incluimos, tanto los útiles como los procedimientos de trabajo o, incluso, lo que sería el propio proceso tradicional de transmisión de los saberes asociados a él, basados en la observación directa y en la repetición imitativa. Por supuesto, este tipo de reclamo turístico genera un recurso económico directo, como es la compra de las piezas, que, a su vez, implica otros valores. En primer lugar, la aprehensión de la experiencia turística en su conjunto —objeto y actividad-, la exclusividad asociada a la 
artesanía y, finalmente, la inclusión de los valores positivos en la forma de vida de una comunidad dentro de los recursos obtenidos por el turista.

En segundo lugar, entre los elementos que interactúan con la recuperación del Barrio dos Muiños, podríamos mencionar la gastronomía. Es bien conocido el potencial de convocatoria que tienen ciertas fiestas de carácter gastronómico, muchas de ellas reconocidas oficialmente. El caso de Mondoñedo no es paradigmático en este sentido, puesto que no existe ningún producto o elaboración del mundo tradicional que se identifique con la villa, probablemente porque la cantidad de recursos de otro tipo, singularmente los históricos y artísticos, han difuminado la explotación de este recurso. La imagen tradicional, casi mítica, que existe en torno a Mondoñedo como ciudad eclesiástica, vinculada a los estudios académicos y al mundo espiritual de la Iglesia, contradice también la visión pantagruélica con la que se recupera, en otros casos, el mundo rural y popular gallego. No se puede olvidar, pues, que Mondoñedo no es exacta y totalmente una entidad rural, sino una villa con una antigua tradición cultural.

Al lado de estas peculiaridades, sin embargo, no deja de llamar la atención que, entre los talleres que funcionan en el Barrio dos Muiños haya uno dedicado a la pastelería. La justificación es obvia, y se debe al hecho de que, en realidad, sí existe un producto gastronómico típico de la villa o que, al menos, así se ha presentado en los últimos decenios, aunque desde un punto de vista comercial privado. Nos referimos a la famosa tarta de Mondoñedo, promocionada por la empresa pastelera O rei das tartas con mayor profusión desde la década de 1980. No se trata, sin embargo, de un producto original de esta pastelería, sino absolutamente tradicional, que fue apropiado en su imagen exterior o turística por este particular - $\mathrm{y}$, de hecho, en buena medida se conserva esa imagen desde fuera-, pero que para los propios mindonienses se integra en sus raíces culinarias más profundas, mostrando incluso objeciones al método de elaboración y de presentación, y también a la calidad, de este producto en su forma industrial ${ }^{22}$. Tal es el mensaje asociado a la ubicación de este taller de pastelería en un espacio concebido para la recuperación de las artesanías: su naturaleza tradicional, pero también la calidad que se deriva de los ingredientes empleados y de su elaboración; valor, por otro lado, vinculado a las experiencias de calidad que el turismo de lo rural y de lo ecológico exige.

No podemos dejar de comentar, en este punto, otro contenido simbóli-

${ }^{22}$ En este sentido, no deja de ser significativo que la nave de producción, exposición y venta de $O$ rei das tartas se haya trasladado al exterior de la villa, concretamente a la carretera que enlaza la capital de la provincia con la zona costera, obligada área de paso, pues, para los turistas de sol y playa. 
co en este producto. Nos referimos al hecho de que se trata de un postre ${ }^{23}$, un alimento dulce, vinculado a las celebraciones o a momentos especiales, sobre todo en el mundo tradicional y que, como tal, su consumo está más ligado a la satisfacción de la gula que del apetito, es decir, más al deleite del espíritu que a la alimentación del cuerpo. Tales valores son los que, sin duda, con mayor precisión se corresponden al contexto simbólico de Mondoñedo como ciudad eclesiástica y espiritual, y también los que favorecen que, en una dimensión turística, la tarta sea percibida con mayor facilidad por los turistas como souvenir o como producto artesanal.

En tercer lugar, también podemos hablar de un elemento comercial y publicitario que interactúa con los restantes para facilitar la creación de una imagen pública del contexto mindoniense, en la que se va a apoyar la recuperación del Barrio dos Muiños. Nos hemos referido en diversos momentos a una serie de actividades que generan un contexto mítico, como pueden ser la propia publicitación a nivel nacional y, sobre todo, gallego, de las tartas como producto típico, pero también, por ejemplo, la existencia de una marca de productos que se identifica con lo gallego como es Rei Zentolo, que toma su nombre de las famosas cuevas mindonienses. Mucho más directamente relacionada con el Barrio dos Muiños y con la propia villa de Mondoñedo se encuentra la serie televisiva Terras de Miranda, que comparte denominación con el GAL local.

Casi en la misma dimensión se encuentra la aportación del elemento literario. Como hemos visto, Mondoñedo es una villa profundamente cunqueiriana, en la que los productos de la imaginación de este autor conviven con las realidades cotidianas, dándole una cierta aura de irrealidad y fantasía. La presencia de personajes que en otro contexto serían extravagantes, como el mago Merlín que, correspondientemente ataviado, atiende su local de libros y artículos de magia compartiendo plaza con la catedral, los lemas publicitarios cunqueirianos que han servido para promocionar la ciudad, la estatua del propio escritor sentado en un banco mirando la plaza de la catedral que actúa como eje de la actividad social, las calles dedicadas a otros escritores o artistas, la dimensión literaria de la obra de Cunqueiro, fuertemente impregnada por la villa y, en definitiva, la creación de la fantápolis de Miranda, suponían un campo perfectamente abonado para la instauración de un recurso turístico en el que la ciudad es un producto y la idealización asociada al pasado, una exigencia. Incluso podríamos pensar que en esta imagen que acabamos de describir Mondoñedo trasciende lo local para

${ }^{23}$ La tarta de Mondoñedo es un postre, nada liviano, en cuya elaboración se utiliza hojaldre, bizcocho, cabello de ángel, almíbar, almendras molidas y frutas confitadas, normalmente higos y cerezas. 
convertirse en una representación de lo gallego, más concretamente de la imagen que se ha proyectado de la Galicia interior. Lo cunqueiriano puede verse muy influido por la imagen ensoñadora y fantasiosa que se atribuye a la imaginería celta, con una muy indudable presencia en la cultura gallega moderna. Esta configuración ideológica colectiva mítica, donde sobresale la materia literaria bretona, el mundo natural y los mitos populares o incluso los espacios físicos y geográficos, forma parte de la idiosincrasia no sólo mindoniense sino gallega en general, al menos desde un punto de vista endógeno, y no cabe duda de que se trata de un elemento de creación de identidad colectiva.

De esta forma, una oferta turística que parta del ofrecimiento de una serie de recursos retomados de la tradición puede ofrecer un carácter integral, que no parece admitir un desconexión entre los elementos que la componen, pero también integrado, en tanto que debe estar enmarcado en las coordenadas de las realidades inmediatas, tradicionales o no, con las que convive. La coherencia parecería una exigencia o, al menos, una buena opción para la construcción de un espacio local aprovechable desde el punto de vista turístico. Un modelo que aparezca desvinculado de ciertas exigencias de carácter global quizás carezca del prestigio necesario para subsistir; nos referimos a la evidencia de que de la globalización emana todo el proceso que lleva a la recuperación de las opciones locales como recurso frente a la propia globalización. Así, por ejemplo, una propuesta turística antiecológica, irrespetuosa con ciertos valores comunes asociados con la idea occidental de la democracia - por ejemplo, que explote y se aproveche de una sociedad tradicional-, desvinculada de las representaciones culturales locales, aculturalizada o carente de manifestaciones que se puedan considerar propias, etc., probablemente dará lugar a que los potenciales visitantes sean reticentes ante ella o que incluso la rechacen. En este sentido, consideramos de especial relevancia destacar que "no se puede ni se debe pensar en exclusividad en el turismo y menos aún en el abandono de otras actividades cuya función es básica en el mantenimiento de la autenticidad de la experiencia turística, en la conservación de prácticas y usos de gran valor cultural" (Vera Rebollo 2000: 326).

El caso de Mondoñedo, ejemplificado en la recuperación del Barrio dos Muiños, parece, en cambio, tener la opción de integrar esos valores ya mencionados y que la sociedad ha sancionado con su beneplácito. Cuando menos, evita entrar en una dinámica de aislamiento de otras opciones que se encuentran funcionando al mismo tiempo y que, a la larga, generaría un efecto indeseado de deslocalización. Por supuesto, esto no garantiza su éxito como un negocio desde el punto de vista exclusivamente económico, y probablemente esto también evite que se plantee este tipo de turismo al 
margen de otras cuestiones de índole social, identitario o simbólico. Sería esta la razón que explicaría por qué deben ser las instituciones las que dirijan e incluso promocionen estas soluciones, porque una concepción privada, en manos de las grandes empresas transnacionales del turismo, centraría su interés en la explotación del negocio en sí, ajena a la participación colectiva y a la organización local, que son quienes, de alguna forma, garantizan la integralidad de la opción, la recuperación de lo social, lo ecológico, lo natural, lo cultural, en definitiva, junto a lo estrictamente económico.

\section{BIBLIOGRAFÍA CITADA}

Aguilar Criado, E. 2003. "La cultura como recurso en las políticas de desarrollo rural. Una lectura desde la globalización", en Cultura y Política. Barcelona: ICA/FAAEE.

Ballart Hernández, J. y J. Juan i Treserras. 2001. Gestión del patrimonio cultural. Barcelona: Ariel.

Beck, U. 2000. Un nuevo mundo feliz. La precariedad del trabajo en la era de la globalización. Barcelona: Paidós.

Castro Allegue, F. M. 2005. Código del Patrimonio Cultural Gallego. Santiago de Compostela: Xunta de Galicia.

Cruces, F. 1998. "Problemas en torno a la restitución del patrimonio. Una visión desde la antropología". Política y Sociedad 27: 77-87.

Fernández Gómez, J. D. 2005. "Eslóganes, jingles y otras frases felices", en M. V. Romero (coord.), Lenguaje publicitario. La seducción permanente: 89-111. Barcelona: Ariel.

García Canclini, N. 1989. Las culturas populares en el capitalismo: México: Nueva Imagen.

García Canclini, N. 2000. La globalización imaginada. Buenos Aires: Paidós.

Giddens, A. 2002. Consecuencias de la modernidad. Madrid: Alianza.

Halbwachs, M. 2004. Los marcos sociales de la memoria. Barcelona: Anthropos.

Instituto Galego de Estadística. 2006. Datos Estadísticos Básicos de Galicia 2006. Santiago de Compostela: Xunta de Galicia.

Pereiro, X. y X. C. Sierra (coords.). 2005. Patrimonio cultural: politizaciones y mercantilizaciones. Sevilla: FAAEE-Fundación El Monte.

Prats, Ll. 1998. "El concepto de patrimonio cultural". Politica y sociedad 27: 63-76.

Prats, Ll. 2005. "Concepto y gestión del patrimonio local". Cuadernos de Antropología Social 21: 17-35.

Romero, M. V. (coord.). 2005. Lenguaje publicitario. La seducción permanente. Barcelona: Ariel.

Secretaría Xeral de Planificación e Desenvolvemento Comarcal. 2000. Memoria. Santiago de Compostela: Xunta de Galicia.

Vera Rebollo, J. F. 2000. "Territorio, medio ambiente y paisaje como argumentos del desarrollo turístico", en J. Hernández Borge, J. A. Díaz Fernández y C. A. Patiño Romarís (coords.), O turismo en Galicia. Potencialidades endóxenas de desenvolvemento urbano e económico: 319-348. Pontevedra: Deputación de Pontevedra.

Verdés Vilaseca, H. 2000. "Promoción y comercialización de un destino turístico", en J. Hernández Borge, J. A. Díaz Fernández y C. A. Patiño Romarís (coords.), O turis- 
mo en Galicia. Potencialidades endóxenas de desenvolvemento urbano e económico: 349-367. Pontevedra: Deputación de Pontevedra

http://ec.europa.eu/agriculture/rur/leaderplus/index_es.htm (consultado en.....)

http://redrural.tragsatec.es/redrural/presentacion_leader.htm (consultado en)

http://www.redr.es/acciones/proderleader.htm (consultado en....)

http://www.artesaniaosmuinos.com/ (consultado en...)

Fecha de recepción: 1 de abril de 2008

Fecha de aceptación: 2 de mayo de 2009 